\title{
INTRODUCTION TO BIOTERRORISM RISK COMMUNICATION
}

\author{
Itay Wiser ${ }^{1}$ and Ran D. Balicer ${ }^{2}$ \\ ${ }^{1}$ Italy Wiser, MD. Department of Epidemiology and Preventive \\ Medicine, School of Public Health, Sackler Faculty of Medicine, \\ Tel Aviv University \\ ${ }^{2}$ Ran D. Balicer, $M D, M P H$ \\ Epidemiology Department, Faculty of Health Sciences, Ben-Gurion \\ University of the Negev, Beer-Sheva, Israel
}

\section{Pre-event}

\subsection{SHOULD WE CURRENTLY INFORM THE PUBLIC ON THE POTENTIAL RISK OF A BIOTERRORISM EVENT? IF SO, HOW?}

One basic paradigm that lies at the base of many risk communication theories claim that the more we trust the people who are supposed to protect and inform us, the less afraid we will be, and the less we trust them, the greater our fears. If the public trusts the government is dealing with a crisis effectively, there will be less public fear. Still, ideal sense of partnership and trust between authorities and the public is far from present, as repeated surveys have shown. A well-planned communication effort should provide clear precautions, reassure the public, reduce unnecessary distress, and limit inappropriate demands on health-care system [1-3].

Different views exist regarding disclosing to the public preparedness plans for various scenarios of bioterrorism and as to the extent in which the public should be involved. The older paradigm claims that people should know only what the communicators want them to know, in order to get them to behave "rationally" during a crisis - i.e., the way the communicator wants them to behave [2]. This model is criticized by risk communication experts to be "overtly manipulative" and unlikely to succeed. Risk communication is more likely to succeed if it sets the more realistic goal of helping people understand the facts, in ways that are relevant to their own lives, feelings, and values, so they are empowered to put the risk in perspective and make more informed choices [4]. More updated models shift towards giving the public a sense of partnership in the emergency, 
rather than conveying the minimum necessary information to keep them calm [5]. Some authors suggest that a citizen advisory panel, comprised of community members respected by and credible to their peers, can be affective mechanism for gaining constructive public participation and dialogue about possible high-concern situations [6].

Public health and media professionals generally agree that the public should be informed, and that risk communication must be tailored to fit specific scenarios, subpopulations and communication media. Still, no consensus exists on the question of how much information should the public be exposed to and what is the appropriate media for it. Furthermore, the scarcity of bioterrorist events makes it even more difficult to reach evidencebased conclusions. Therefore, risk communication experts rely mainly on behavioral theories when planning communication strategies, designing media messages, and analyzing public feedback.

Growing awareness to public communication issues has revolutionized risk communication policies. To prepare risk communication plans at the population level, models such as social amplification of risk model, may be implemented. This model is based on the theory that risk events are portrayed through various signs and images in the media, which interact with a range of psychological, social, institutional, and cultural processes that intensify or attenuate risk perceptions. This model may be helpful in analyzing the ability of agencies to work together, and it highlights the importance of incorporating feedback from the public and media to allow ongoing improvement. On that matter, recent research has established the utility of rapid polling for making informed government responses in an ongoing emergency [7].

Many of the health and risk communication theorists emphasize the need for the careful crafting of the message to be delivered, the choice of suitable and credible spokespersons, timing of message delivery, and the appropriate selection of communication channels [8,9]. Others stress out the importance of a thorough situational analysis, consideration of the emotional and political climate, provision of information to meet the needs of the intended audience, and respect for people's capacities [10,11].

In view of the challenges associated with heterogeneous literacy among various subpopulations, efforts should be directed at drafting messages that can reach and be understood by as many target groups as possible. This would enhance the chances that the messages will be centrally processed and achieve the best results, as outlined by the elaboration likelihood model (ELM) [12]. The ELM is based on the individual's ability to process a message and determine whether it is processed through "central" or "peripheral" route. Each route may lead to persuasive results, but the central route, which is correlated with high motivation and better message-processing 
mechanisms, leads to more enduring attitude and behavioral change [13]. Under circumstances of an attack, its mere threat may produce less motivation, and together with high levels of illiteracy in the American public, may be the cause of diminished ability to process complicated messages, thus leading to "peripheral route" message processing.

At the individual level, models such as McGuire's persuasion/communication model assist in increasing the likelihood of reaching an effective message by analyzing the characteristics of the input message (agency reputation, message content, and media channel) and their effect on the output (levels of persuasion and behavioral change as a result). Studies have recently shown that most local public health and health-care professionals lack adequate training and resources to carry out important communication functions. The persuasion/communication model can serve a guideline for health professional training in risk communication [5, 14].

\subsection{HOW CAN WE PREPARE NOW IN ORDER TO PERFORM BETTER RISK COMMUNICATION DURING AN EVENT?}

Lessons from the anthrax mail bioterrorist attack stress out the need to prepare in advance to a bioterrorist event. Such preparedness efforts should include:

1. Ensuring collaboration and integration of agencies responsible for communication

2. Establish communication planning for bioterrorism preparedness

3. Estimate public risk perceptions

4. Prepare media information protocols in advance

5. Develop effective media-based dissemination plans

6. Design open, accurate, and consistent messages and ensure ethical approach to communication preparedness [15].

To maintain an effective risk communication policy, we should assess key elements in the public perception of risk such as familiarity of the risk, its potential damage, level of public uncertainty, public sense of control, and public trust in authorities. Legitimate sense of control can be given to those under threat, especially in advance of an attack, by public education, by public participation in the preparation process, and by providing the public a voice in the decisions that will affect them $[6,16]$.

The use of quantifiable scientific methods such as surveys, polls, and public interviews among various subpopulations can help identify the key risk communication messages that audiences want, need and are the most likely to be effective. A systematic communication program should begin 
with formal analyses identifying the core set of critical facts that impact the individuals' decision-making process, and proceed to create, evaluate, and disseminate appropriate messages. Its success could be determined with a tracking survey, assessing public mastery of those facts $[2,17,18]$.

Such evidence-based data is scarce. For example, the National Institute of Mental Health's (NIMH, 2002) consensus report on early intervention after mass trauma acknowledges that the current evidence from randomized, well-controlled trials cannot definitively confirm or refute the effectiveness of such early interventions. However, even this limited evidence does permit several conclusions:

1. Any early intervention should consider the hierarchy of a victim's needs, including safety, food, and shelter.

2. The important elements of early intervention activities are an assessment of needs, the dissemination of information and the education of directly affected individuals and the general public, and the facilitation of natural support networks [19].

Rudd et al. have compared two communication efforts made by the government concerning the AIDS/HIV epidemic in 1988 and 2001 postcard sent following the anthrax letters incident. Their comparison had uncovered several important lessons:

1. Although mass mailing has a limited communication medium due to its unidirectionality, it puts critical information in the hands of a large group of people and hence is a powerful tool.

2. Over 250 studies show that health-related print materials are far exceeding the reading ability of the average adult and so health communication efforts must be tailored to the literacy skills of the intended audience.

3. The importance of pre- and post-evaluation - developers of the anthrax postcard did not have as much time to seek expert advice and field-test their mailing, and hence some of the information presented was not properly understood. Generic and disease-specific communication materials should therefore be prepared and field-tested before an event occurs.

4. During crisis events, the unexpected takes center stage and recommended steps for developing communication efforts may not be followed rigorously. However, when communication planners abandon rigor in the name of expediency, effectiveness may suffer. To avoid the need for such a choice, the public health establishment should identify critical structures and processes that it could employ to improve communications in times of crisis. 
Several of these lessons were suggested years ago, but they have not been implemented into practice towards the next crisis. On 22-23 June 2001, a senior-level exercise entitled "Dark Winter" that simulated a covert smallpox attack on the United States was held. First exercise of its kind, Dark Winter was constructed to examine the challenges that seniorlevel policy makers would face if confronted with a bioterrorist attack that initiated outbreaks of highly contagious disease. The exercise was intended to increase awareness to the threat posed by biological weapons and to bring about actions that would improve prevention and response strategies. One of the conclusions from the simulation was that individual actions of US citizens are critical to ending the spread of contagious disease and therefore leaders must gain the trust and sustained cooperation of the American people. This conclusion, unfortunately, have been challenged unsuccessfully in the response to the 2001 anthrax attacks, when public officials failed to gain sufficient public trust and form a consistent and accurate risk communication to the public [20].

\subsection{WHAT IS THE ROLE OF THE INTERNET IN RISK COMMUNICATION BEFORE AND DURING AN EVENT?}

Critiques of information dissemination in response to the events of 11 September 2001, highlight new increasingly important role of the Internet as an information channel and the need for strategically coordinating what is often conflicting information. For example, one analysis recognized the importance of the Internet in providing up-to-the-minute information, but also its potential for increasing confusion and uncertainty through rapid, often-uncontrolled proliferation of information and spread of rumors. Others noted that information was coming from so many sources and transmitters, it was often more confusing and contradictory than it was helpful. Thus, it is all the more essential to plan carefully to ensure consistency of messages across channels. It is also critical to conduct research to assess how the media have covered past emergencies and to better understand norms and practices of journalists in covering emergencies [5].

A key advantage the Internet has over traditional media is that the Internet provides multiple branches of information, all accessible almost simultaneously, which the user can easily maneuver between. During the anthrax threat, the Internet also allowed for innovative communication devices such as interactive tutorials on anthrax self-care (such as "X-Plain Online" from the Patient Education Institute, 2002). Furthermore, the information provided could be customized for specific interest groups. For example, asthmatics may have had different concerns from those of the 
general population, just as postal workers had different needs from those of the general public during the anthrax threat.

In the 2 days after the terrorist attacks, one out of four Internet users went online in addition to monitoring television and radio reports. This suggests that the Internet may aid in assessing the credibility of information users have obtained from the traditional media [21].

The Internet also allows great scope for forward planning and dissemination of information. For example, the CDC now has detailed guidelines on anthrax management on its site, and in addition, it has published guidelines as to how individuals and agencies should act in the case of outbreaks of diseases like smallpox and typhoid [1].

Information on the Internet is available to users at any time of day, and increasingly from the home. This is especially salient given that during the height of the bioterrorist threat many people were likely afraid to travel away from home. In some cases, when a number of cities issued warnings of potential threat, people preferred to stay at home or close to home; one survey published on September 15 found that "about 9\% of Americans say that in the first two days after the terror attacks they cancelled some travel plans" [21].

The Internet can serve also as a "therapeutic" medium as documented during the Gulf War. When Israeli citizens were shut in sealed rooms during the Persian Gulf War, some found the nascent Internet an essential tool in maintaining psychological stability and a way to communicate with the outside world [22].

Although the above advantages of Internet as a tool for risk communication, several challenges should be considered:

1. Internet users have no definitive way to assess web site credibility and accuracy, and thus can be mislead and misinterpret the risk level. As a result, Internet has the potential not only to help but also to harm effective risk communication policy.

2. Search engines play a key role in organizing information for the public during a bioterrorist attack. The Internet industry in cooperation with the government should develop transparent protocols for organizing key information during emergency situations so that credible and validated sites are called up first when people search for information. In addition, there is a need for more systematic regulatory oversight of web site content with the promulgation of clear industry standards, as is done in the television and radio industries.

3. Several subpopulations do not have access to the Internet. The Internet cannot therefore be regarded as an exclusive data source in times of crisis. 
4. There has been limited analysis of the general impact of Internet-based health information on behavior. However, there is some evidence that health information on the Internet does affect people's management and response to health risk. The Pew Internet and American Life Project has found that $61 \%$ of those who searched online for health information - or about 43 million Americans - said that the information they found on the web improved the way they take care of themselves. In addition, $44 \%$ of those who found the health information they sought online said it affected a decision about how to treat an illness or condition and $38 \%$ said it lead them to ask a doctor new questions [21].

To summarize, the Internet can serve as an attractive risk communication tool, before and during crisis. However, Public leaders should take into account its yet limited population exposure, credibility issues, and the need for internet industry cooperation.

\subsection{HOW SHOULD WE EDUCATE THE MEDIA BEFORE AND DURING AN EVENT?}

The public health community has come to recognize that the media are influential actors and determinants of health behavior and outcomes [23]. These two groups (public health community and the media) rely on each other in many ways, yet have different goals. Building Credible relationship with the press can assist authorized officials to convey public messages and guidance [5].

The role of the media is central in several risk communication theories, such as social amplification model. This model takes under consideration norms and practices of news organizations that structure how events are reported. For instance, journalists favor "legitimated" institutional sources that give a sense of authority and credibility to new reports [5]. The media needs to be monitored consistently during an emergency to ensure that information being told is accurate [24].

Following bioterrorism preparedness exercises and the September 11 attacks it has became evident that the public will turn to public health leaders for information [20]. As a result there has been growing emphasis on the need for a complete public health provider - media interface that should include pre-prepared situation specific message formats, an appointed public information officer. Another lesson learned from these experiences is that maintaining an open and proactive relationship with the press in an emergency may enhance message effectiveness by enhancing community trust [25]. 
Risk communication policy makers should take under consideration that journalists' attention is mostly to newsworthy information and not just information of public health importance. A recent study highlights the difficulty of getting public health messages through to news audiences when the public health crisis is embedded in a larger, complex story, as happened in the anthrax attacks that came on the heels of September 11. As a result, news media had less of a focus on the public health side of anthrax than did the CDC [26].

\section{Once an Outbreak Occurs}

Effective risk communication is a serious challenge during crisis events. At such times, people have difficulty processing information and hearing, understanding, and remembering what they have been told. An environment of uncertainty and ambiguity leads many to a heightened sense of anxiety. People have a tendency to assume the worst and, as a result, their distrust of government and experts may also be heightened [27].

\subsection{GENERALLY, WE SHOULD TELL THE TRUTH SHOULD WE TELL ALL THE TRUTH? ALWAYS?}

Officials may believe that they are protecting the public by withholding information regarding response plans on the theory that revealing these plans will indicate potential attackers where they can strike most effectively [28]. The attacks of 2001 have shown that determined terrorists will identify vulnerabilities that are unknown to the public. More importantly, this approach ignores the role that citizens can and should play in helping set state and local priorities [29]. Based on experience in contemporary and historic outbreaks, emphasizing the public's autonomy when implementing epidemic controls can actually help minimize the number of cases and deaths $[30,31]$.

The Chinese severe acute respiratory syndrome (SARS) risk communication policy serves as an example to possible damage when withholding information from the public. During the SARS crisis, Chinese officials had withheld frequent updates from the public coupled with surreptitious disease containment. As the epidemic spread across China, provincial leaders withheld information from peasants on the theory that "They just won't understand" [32]. But when peasants learned their villages might be used to quarantine outsiders who had possibly been exposed to SARS, they rioted against government preparation of quarantine centers and set up makeshift roadblocks to keep out nonresidents. 
Authorities should approach members of the public as peers, as decision-makers who are interested in determining the nature of the danger and acting to reduce the chance of illness for themselves and loved ones [33]. Experience from the anthrax letters bioterrorist attacks shows that the public places more trust in updates coming from public health officials and physicians than from appointees who do not have health backgrounds [34].

Decision-makers should avoid thinking that members of the public are panicking when they are merely engaging in entirely understandable behaviors, such as seeking more information, questioning authorities, and undertaking precautionary measures (even if officials believe these are unwarranted). Rather than dismissing expressions of fear, dread, or misery, leaders should acknowledge people's sense of vulnerability and ask them to bear the risk and work together toward solutions [35].

Telling all the truth sometimes might do damage as well, especially when providing public health "good news" that are unproved or quickly refuted. An excellent example is the German and Japanese announcements of premature termination of bovine spongiform encephalopathy (BSE) crisis. In November 2000, German agriculture minister Funke declared confidently that Germany was immune from BSE. Funke essentially said to the German public, "Trust us. You're safe". One week later the first sick cow was found. Not only did this create fear of the disease, but Funke's statements damaged public trust in government, and beef sales plummeted nationwide [2]. Consider the German government's response included the resignation of Funke, and his replacement with a green party member who promised to make the Ministry of Agriculture more aware of consumers' concerns. These symbolic actions were not intended to deal with the physical risk. Rather, they recognized the peril from fear and the reality that public perceptions of mad cow disease were a very real part of the problem. This was an example of effective risk communication, with actions as well as words. Trust was restored, and despite subsequent identification of more sick cattle, within a few months beef sales had returned nearly to normal.

In a similar case, following the first case of BSE was confirmed in Japan (10 September 2001), agriculture minister Takebe foolishly promised that there would not be any others. The second sick animal was found just days later. Takebe also said that the first sick animal had not been rendered into protein and put into the cattle food supply, so the disease could not spread. Within days, the government had to admit that it was wrong and that the first animal had indeed been used to produce protein for cattle feed. The press revealed that the Japanese government had suppressed a European Union document that reported that Japan was at high risk for BSE, and also had 
failed to impose controls on the cattle and dairy industry to keep the disease from spreading. Takebe made his third mistake by trying to reassure the public by sacking an assistant and publicly eating beef to show that it was safe. Takebe did not resign. Although fewer sick cattle have been found in Japan than in Germany, beef sales in Japan were still off dramatically months later, much longer than it took for German beef sales to recover [2].

\subsection{WILL WE BE ABLE TO CONTINUOUSLY UPDATE THE PUBLIC?}

Following the 9/11 attacks, Mayor Giuliani exemplified what leaders should do when faced with uncertainty. Able to offer only a rough estimate of 9/11 casualties early on, he indicated that the final number would be "more than any of us can bear, ultimately." A question of utmost importance to the public, but one that cannot be easily answered in the initial stages of a biological attack will be: "How many sick and dying are there?" As noted earlier, leaders will face a host of other questions to which there are no quick and sure answers, such as whether an outbreak is a precursor to other attacks [29].

Through early and frequent media briefings, a leader can demonstrate a commitment to keeping the public up-to-date. This practice can also help avert an official information void that may be filled by harmful speculation or less dependable sources [29]. Steps toward effective interactions with the media include setting aside any predisposition to see the press as intruders or provocateurs, establishing positive working relationships with them prior to a crisis, developing a pragmatic communications strategy to deal with the reality of 24/7/60/60 reporting, and picking and training appropriate spokespersons. Incorporating the press in training exercises improves understanding between officials and the media of their roles and challenges in a bioterrorism response. When an event occurs, leaders often believe that they are too busy managing the response to spend time with the press and, by extension, the public. Although there is some truth in this, decision-makers should appreciate that responding to the public's concerns is not a distraction from managing the crisis, but rather is part and parcel of managing the crisis.

Telephone-based hotlines provide both up-to-date information to the public and public feedback tool. A telephone bank at CDC during an outbreak of Hantavirus pulmonary syndrome identified $38 \%$ of confirmed cases [36]. Computerization of the system would allow for timely transfer and analysis of complete and accurate telephone call data and perhaps provide a similar layer of passive surveillance for emerging bioterrorism events [37]. 
Hospital personnel, private practitioners, and emergency medical workers are understandably going to be interested in their well-being and that of their families during a health emergency. Health officials and their organizational collaborators should also ensure that these critical personnel have the information they need to reduce any unwarranted reluctance to do their jobs [29].

To summarize, providing rapid and accurate information to the public during a bioterrorist event is, therefore, critical to reducing uncertainty (US Department of Health and Human Services, 2002) and should be joined by the efforts of local, state, and federal governments to enhance surveillance for a bioterrorist attack and increase lab capacity to rapidly identify a bioterrorist agent [19].

The need for readily available health care and specially trained providers cannot be underestimated. The Gulf War syndrome controversy demonstrates how complex health issues can become after a possible CBN attack and how important it is for health-care providers to have up-to-date information. When a traumatized population cannot obtain answers to health questions from knowledgeable providers, misinformation fills the void and concerns multiply. Moreover, specially trained providers could maintain standardized medical records, which are important for scientific and medical-legal purposes [38].

Several experts emphasize the importance of local risk communication strategies to complement the information likely to be provided by national authorities. According to one expert, "We really don't understand the psychological context in which we are delivering our messages, nor whether they are really addressing the needs of the community. We need to better understand [it] so we can modify our messages and target our outreach" [19].

\subsection{HOW REASSURING SHOULD WE BE?}

At the very outset of a biological attack, leaders should prepare the community for conditions of uncertainty and a potentially prolonged crisis. Realistic descriptions of the tentative and evolving nature of authorities' understanding can offset public perceptions regarding an omniscient, omnipotent government on the one hand, or an utterly incompetent one on the other.

Over reassurance can lead to public mistrust, especially when the situation worsens. The anthrax letters case supplied good examples to it. You do not need to be an SRA president, Surgeon General, or risk communication guru to see problems in federal agencies' communication 
about anthrax during the fall of 2001. Among the examples noted by reporters:

1. Providing inappropriately reassuring information: Health and Human Services Secretary Tommy G. Thompson announced that initial victim Robert Stevens had probably been exposed to anthrax in the woods of North Carolina, even though scientists indicated that this was highly improbable.

2. Downplaying uncertainty: Federal officials initially dismissed the possibility that mail containing anthrax could be dangerous to postal employees.

3. Delaying release of information: CDC spokespeople voiced frustration at having little to report to the public because of the FBI's reluctance to share vital information. Similarly, while FBI officials had known about the suspicious letters sent to NBC since September 25, New York City officials were first notified of the situation by a doctor who treated one of the victims several days later [39].

\section{Reference}

1. Hobbs J, Kittler A, Fox S, Middleton B, Bates DW. Communicating health information to an alarmed public facing a threat such as a bioterrorist attack. $\mathrm{J}$ Health Commun 2004; 9(1):67-75.

2. Gray GM, Ropeik DP. Dealing with the dangers of fear: the role of risk communication. Health Aff (Millwood) 2002; 21(6):106-116.

3. Lofstedt RE. Risk communication: the Barseback Nuclear Plant case. Energy Policy 1996; 24(4):689-696.

4. Jasanoff S. Differences in national approaches to risk assessment and management. In: Symposium on managing the problem of industrial hazards: the international policy issues. Washington, DC: National Academy of Sciences, 1989.

5. Wray RJ, Kreuter MW, Jacobsen H, Clements B, Evans RG. Theoretical perspectives on public communication preparedness for terrorist attacks. Fam Commun Health 2004; 27(3):232-241.

6. Covello VT, Peters RG, Wojtecki JG, Hyde RC. Risk communication, the West Nile virus epidemic, and bioterrorism: responding to the communication challenges posed by the intentional or unintentional release of a pathogen in an urban setting. J Urban Health 2001; 78(2):382-391.

7. Blendon RJ, Benson JM, Desroches CM, Weldon KJ. Using opinion surveys to track the public's response to a bioterrorist attack. J Health Commun 2003; 8(Suppl 1):83-92; discussion 148-151.

8. Sandman PM. Hazard versus outrage in the public perception of risk. In: Covello V, McCallum D (eds). Effective risk communication: the role and 
responsibility of government and non-government organizations. New York: Plenum Press, 1989, pp. 45-49.

9. Covello VT. Communicating risk information: a guide to environmental communication in crisis and non-crisis situations. In: Kolluru R (ed.). Environmental strategies handbook: a guide to effective policies and practices. New York: McGraw-Hill, 1998, pp. 359-373.

10. Wallack L. Two approaches to health promotion in the mass media. World Health Forum 1990; 11(2):143-154; discussion 155-164.

11. Backer TE, Rogers EM, Sopory P. Designing health communication campaigns: what works? Newbury Park, CA: Sage Publications, 1992.

12. Zarcadoolas C, Pleasant A, Greer DS. Elaborating a definition of health literacy: a commentary. J Health Commun 2003; 8(Suppl 1):119-120.

13. Petty R, Barden J, Wheeler S. The elaboration likelihood model of persuasion: health promotions that yield sustained behavioral change. In: DiClemente R, Crosby R, Kegeler M (eds). Emerging theories in health promotion practice and research: strategies for improving public health. San Francisco: Wiley, 2002, pp. 71-99.

14. Evans RG, Crutcher JM, Shadel B, Clements B, Bronze MS. Terrorism from a public health perspective. Am J Med Sci 2002; 323(6):291-298.

15. McLcan V. Partnership for public warning. A national strategy for integrated public warning policy and capability, 2003.

16. Slovic P, Fischoff B, Lichtenstein S. Facts and fears: understanding perceived risk. In: Schwing D, Albers R (eds). Societal risk assessment: how safe is safe enough? New York: Plenum Press, 1980, pp. 181-216.

17. Morgan MG. Risk communication: a mental models approach. Cambridge: Cambridge University Press, 2002.

18. Fischhoff B, Gonzalez RM, Small DA, Lerner JS. Evaluating the success of terror risk communications. Biosecur Bioterror 2003; 1(4):255-258.

19. Stein BD, Tanielian TL, Eisenman DP, Keyser DJ, Burnam MA, Pincus HA. Emotional and behavioral consequences of bioterrorism: planning a public health response. Milbank Q 2004; 82(3):413-455, table of contents.

20. O'Toole T, Mair M, Inglesby TV. Shining light on "Dark Winter". Clin Infect Dis 2002; 34(7):972-983.

21. Rainie L. Pew Internet and American Life Project Report: how Americans used the internet after the terror attack, 2002.

22. Ritchie EC, Friedman M, Watson P, Ursano R, Wessely S, Flynn B. Mass violence and early mental health intervention: a proposed application of best practice guidelines to chemical, biological, and radiological attacks. Mil Med 2004; 169(8):575-579.

23. Institute of Medicine. The Future of the Public's health in the 21st century. Washington, DC: National Academies Press, 2003.

24. Prue CE, Lackey C, Swenarski L, Gantt JM. Communication monitoring: shaping CDC's emergency risk communication efforts. J Health Commun 2003; 8(Suppl 1):35-49; discussion 148-151. 
25. Bennett P. Understanding responses to risk: some basic findings. In: Bennett P, Calman K (eds). Risk communication and public health. Oxford: Oxford University Press, 1999, pp. 3-19.

26. Mebane F, Temin S, Parvanta CF. Communicating anthrax in 2001: a comparison of CDC information and print media accounts. J Health Commun 2003; 8(Suppl 1):50-82; discussion 148-151.

27. Rudd RE, Comings JP, Hyde JN. Leave no one behind: improving health and risk communication through attention to literacy. J Health Commun 2003; 8(Suppl 1):104-115.

28. Connolly C. Bioterrorism preparedness still lacking, health group concludes. Washington Post, 12 December 2003, A02.

29. Leading during bioattacks and epidemics with the public's trust and help. Biosecur Bioterror 2004; 2(1):25-40.

30. Leavitt JW. Public resistance or cooperation? A tale of smallpox in two cities. Biosecur Bioterror 2003; 1(3):185-192.

31. Annas GJ. Bioterrorism, public health, and civil liberties. N Engl J Med 2002; 346(17):1337-1342.

32. Beech $H$. The quarantine blues: with suspected SARS patients getting dumped in their backyards, China's villagers rebel. Time Asia Magazine, 19 May 2003.

33. Blendon RJ, Benson JM, DesRoches CM, Pollard WE, Parvanta C, Herrmann MJ. The impact of anthrax attacks on the American public. MedGenMed 2002; 4(2):1.

34. Survey shows Americans not panicking over anthrax, but starting to take steps to protect themselves against possible bioterrorist attacks. Harvard School of Public Health press release.

35. Centers for Disease Control and Prevention. Crisis and emergency risk communication. Atlanta, GA: CDC, 2002.

36. Tappero JW, Khan AS, Pinner RW, Wenger JD, Graber JM, Armstrong LR, et al. Utility of emergency, telephone-based national surveillance for Hantavirus pulmonary syndrome. Hantavirus Task Force. JAMA 1996; 275(5):398-400.

37. Mott JA, Treadwell TA, Hennessy TW, Rosenberg PA, Wolfe MI, Brown $\mathrm{CM}$, et al. Call-tracking data and the public health response to bioterrorismrelated anthrax. Emerg Infect Dis 2002; 8(10):1088-1092.

38. Hyams KC, Murphy FM, Wessely S. Responding to chemical, biological, or nuclear terrorism: the indirect and long-term health effects may present the greatest challenge. J Health Polit Policy Law 2002; 27(2):273-291.

39. Chess C, Celia J. Risk communication is a key to dealing effectively with bioterrorism. Risk Anal 2002; 22(6):1039-1040. 